\title{
The performance of employed and unemployed learners on learnership programmes in South Africa
}

\author{
Martha H. Grewe ${ }^{1}$, Wilfred I. Ukpere ${ }^{2 \star}$ and Abraham A. Rust ${ }^{1}$ \\ ${ }^{1}$ Faculty of Business, Cape Peninsula University of Technology (CPUT), Cape Town, South Africa. \\ 2Department of Industrial Psychology and People Management, Faculty of Management, \\ University of Johannesburg, South Africa.
}

Accepted 17 October, 2012

\begin{abstract}
Several critics have questioned the efficiency of learnerships in general in the South African education and human resources management environment. Concerns have been raised regarding the effective management within each sector education training authority (SETA), the management of finances within the respective SETA's and whether the human resource development (HRD) strategy meets its targets. The main objective of this study was to identify the reasons behind this disparity in learners' performance. If employed learners have a higher success rate than that of unemployed learners, then the assumption can be made that the objectives of the Skills Development Act (97 of 1998) are then not being met. However, this research has conversely shown that unemployed learners perform better in learnerships than employed learners. This paper offers academics insight into the difference between employed and unemployed learners' performance during a learnership. If the purpose of the Skills Development Act, 97 of 1998, is to improve the quality life of workers and to assist work seekers in finding work: Why then are unemployment rates still on the increase in South Africa; are learnerships not being implemented correctly or, are employers not recruiting the correct profile of learners on a learnership programme?
\end{abstract}

Key words: Employed, unemployed, learners, learnership, performance, programme

\section{INTRODUCTION}

South Africa has gone through many political changes in its history. Prior to 1981, racial discrimination was prevalent to the extent that it was illegal for Black people to be part of any training initiatives (Bendix, 2000). The Wiehan Commission was appointed by the then government to investigate these matters in 1977. Following this investigation, the Manpower Training Act was passed in 1981 (Van Dyk et al., 2001:3). As a result of this Act, a tripartite alliance was formed in which the National Training Board had to keep the relevant Minister of Manpower (now called Minister of Labour) updated on all training matters. In 1991 this Act was once again amended and the Industry Training Board was established. This was the start of apprenticeships, and also of learnerships (Van Dyk et al., 2001:35). The training environment should not be seen in isolation (Bushney,

*Corresponding author. E-mail: wiukpere@uj.ac.za.
2003), the economy, political and social stance of the country should also be taken into consideration when addressing this topic. There has been a great deal of criticism lodged against South Africa's training system, due to the fact that it cannot effectively meet the demands of the training environment (Van Dyk et al., 2001:35). The current government is faced with many challenges; and realises that if South Africa wants to be a global player, much more focus should be placed on training and development.

\section{Statement of the research problem}

South Africa is faced with enormous skills shortages. This major challenge to national and economic development has prompted the government to enact the Skills Development Act (SDA Act 97 of 1998). One of the fundamental ways of skill development is through learnership programmes. One of the main objectives of the Skills Development Act (no 97 of 1998) is to improve 
productivity in the workplace and to increase the competitiveness between employers. Another fundamental aim of the SDA is to encourage workers to participate in learnership and other training programmes. Should employers be hasty to only send internal employees on training, it will not support the aims of the Skills Development Act. The main issue in learnership programmes in South Africa is that there are two different sets of learners namely, the employed and unemployed learners. For the fact that these two sets of learners have different characteristics and opportunity space, it could be inferred that the employed learners will naturally perform better than the unemployed learners, owing to the fact that they are more educated, experienced, on the job, comfortable, just to mention a few. A difference in performance between employed and unemployed learners may also not stimulate the eagerness to get involved in learnership programmes. However, the problem is that uncertainty still exists with regards to the relative/comparative performance of these two sets of learners on learnership programmes, owing to the fact that no previous research has been conducted to establish the variance in terms of performance between the employed and unemployed learners on learnership programmes in South Africa.

\section{Research questions}

The study seeks answers for the following questions.

1. What characteristic differences exist between employed and unemployed learners that will affect their performance during a learnership?

2. What problems or challenges exist for learners who attend a learnership programme?

3. Are unemployed learners encouraged by the fact that they receive a financial gain during the learnership to such an extent that it will influence their performance positively?

4. Are the performances of unemployed learners during a learnership better, because they know, after a successful completion of the learnership programme, they have a better chance of finding a permanent position?

\section{Objective of the study}

The following are the objectives of the study:

1. To determine why, if any, there is a disparity between the performance of an employed and an unemployed learners whilst on a learnership;

2. To explore the particular problems experienced by learners during their learnerships;

3. To establish to what extent the potential for financial gain as well as future employment, act as motivational factors for unemployed learners to enrol on learnerships.

\section{Motivation and significance of the study}

In accordance with the Skills Development Act (SDA), section 10(1) (a), each SETA is required to develop a sector skills plan, within the framework of the national skills development strategy (NSDS). Sector skills plans are five-year plans prepared by SETAs, aimed at identifying the skills needs of the industry/economic sectors (skills shortages, skills gaps and skills supply) based on the standard industrial classification codes allocated to each individual SETA by the Minister in the SETA establishment and re-certification process as well as the possibilities and constraints in the effective utilisation and development of skills in relation to government's priorities and the objectives of the HRDS, the NSDS, provincial growth and development strategies (PGDS) (including major projects) and relevant industry/economic strategies. The Department of Higher Education and Training (DHET) has developed a guideline which will help SETAs to plan training interventions which will result in employment for those trained (the unemployed learners) and productivity improvements for those who are employed already. The outcome of this investigation will furthermore assist skills development facilitators in the recruitment and selection process of employed and unemployed learners who enters into a learnership agreement. This will assist skills development stakeholders to determine the targets set for each sector skills plans (SSP) and complete the annual training plan.

\section{Theoretical framework}

The theoretical grounding of the investigation is based on the major objectives and - the interpretation thereof - of the Skills Development Act.

\section{The aim of instituting learnerships}

Learnerships are structured programmes which combine classroom and practical training towards the achievement of a formal qualification (Swart, et al., 2005). There are two broad categories of learners that take part in learnerships, namely employed learners - referred to as the internal employees of the business being placed on a learnership; and unemployed learners - referred to as unemployed individuals who are employed just for the duration and the purpose of the learnership.

In South Africa, approximately $27 \%$ of the country's economically active population is illiterate, that is, has a Grade 5 or lower qualification, or no schooling at all. Literacy levels in South Africa remain low, despite a number of literacy programmes run by the private sector and government departments. About $67 \%$ of persons aged 15 years and older are considered functionally illiterate. About $45 \%$ of the population with no education 
were employed in the formal sector with no educational background (Erasmus and Nel, 2007: 50). Early 2011, South Africa entered into an economic recession for the first time in 17 years and it was reported that South Africa has the highest unemployment rate among the world's 50 biggest economies (Naidu-Ghelani, 2012).

In an attempt to address the skills shortage, the Skills Development Act (SDA), together with SAQA, introduced learnerships that are linked to the national qualification framework (NQF). The aim of learnerships is to increase the current labour markets' educational levels as well as the future new recruits entering the world of work. A further attempt to address the skills shortage was done by the Department of Labour when they implemented the Skills Development Act (no. 97 of 1998) in order to develop the skills of the South African workforce and to increase the levels of investment in education and training in the labour market and to improve the return on that investment. One of the most crucial aspects of the Act is that it will improve the employment prospects of persons previously disadvantaged by unfair discrimination and it will redress those disadvantages through training and education (Van Dyk et al., 2002: 36). To train and develop learners money is needed and therefore the birth of a financial framework comprising of the National Skills Authority and the National Skills Fund. A further financial framework is the skills development levy-grant scheme whereby SETAs and labour centres receive money to train people.

Twenty-five SETA's were established by the former Minister of Labour, Mr. Madladlana on the 20th of March 2000. It is the responsibility of the Minister of Labour to ensure that there is a SETA representing each sector within the job market. Each SETA has an obligation to make a definite impact to skills development. If SETAs fail to work properly (mismanaging money, or fails to represents its sector properly), the Minister of Labour can, after consulting the National Skills Authority, request the Director General to take over the administration of the SETA. The Minister may suspend the SETA and take any actions that are needed to get it working again.

SETAs must implement their sector skills plan by establishing learnerships and by approving workplace skills plans (WSPs). Furthermore, SETAs must allocate grants in the prescribed manner to employers, education and training providers and workers; and, they are required to monitor education and training in the sector. The Skills Development Act further states that all SETAs must promote learnerships by identifying workplaces for practical work experience; supporting the development of learning material; improving the facilitation of learning; and assisting in the conclusion of learnership agreements.

\section{The role of the state}

The state's role in the educational process is to ensure that the employers pay their skills levy to SARS (South African Revenue Services). Each SETA then receives a portion of this money to provide quality education to all learners who forms part of a learning programme. The state also has to ensure that the previously disadvantaged unemployed learner and employed learners receive the same quality of training. Employers' social responsibility also plays a vital role in ensuring that all learners are trained and assessed properly by funding the learning programmes. Employers who are able to submit their workplace skills plan and conduct the actual training, can receive up to $70 \%$ of the money they invested to train the learners, back from government.

\section{RESEARCH METHODOLOGY}

A quantitative and qualitative research methodology was used to obtain information. The following qualitative research methodologies were used to collect data: individual interviews, observations and focus groups (Alreck \& Settle, 1985). With observations, data was collected to obtain the behaviour of the learner through their own individual history, background, personal opinion and experiences (Bayat \& Fox, 2007). Semi structured interview questions were send to selected employed and unemployed learners and face to face interviews were held with subject matter experts in the field of learnerships. The quantitative method involves the use of questionnaires, with closed ended questions to obtain relevant information (Babbie \& Mouton, 2001). A sample of 50 unemployed and 50 employed learners were conveniently selected. The purpose of this research was to critically compare the difference in the performance of employed and unemployed learners on a learnership programme. During the comparison, all differences and similarities were identified.

In this study, the achievements of employed and unemployed learners on a learnership were investigated, and not something as concrete as weight and height of these learners. Variables were created to ensure that two or more distinct values were determined. All analysed data were properly utilised to reach a suitable conclusion (Vanderstoep and Johnston, 2009:48). The data was collected by sending out questionnaires to the respondents that consist of the employed and unemployed learners who formed part of the learnerships. Interviews were also conducted with subject experts and people working in the field of training and development such as trainers, assessors and moderators.

The employed and unemployed learner's academic records were requested from the training providers and used for the research. Data were also collected by means of observing these learners during facilitation and assessment sessions.

The questions that were asked in the questionnaire were essential questions that needed to be asked in order to source the data needed. Information such as the purpose for being on the learnership, age, gender, personality and individual behaviour and educational background were some of the main questions that were asked to both the employed and the unemployed learners. The only independent variable that was used is the employment status of the learner while on the learnership. The questionnaire was userfriendly and learners had no ambiguity on how to complete the questionnaire. No leading questions formed part of the questionnaire, nor were key terms used that was too difficult for the learners to understand. The employed and unemployed learners were observed to analyse events of interest such as behaviour, absenteeism and results.

Using observations as a research technique requires a lot of attention and planning (Richards and Morse, 2007). Learners were not made aware that their behaviour in class was being observed 
for the purpose of the research as it may have caused learners to react differently from their normal behaviour. Fortunately the research was conducted over a long period, so the probability that learners would change their behaviour was unlikely. The population in this study consists of employed and unemployed learners on learnerships. This population resides in the Western Cape, which made it cost and time effective to conduct the investigation. During the data collection stage no possible ethical problems were detected.

\section{DATA ANALYSIS}

Once the appropriate research design and suitable means to measure the data was chosen, the data was analysed. The results were drawn from the questionnaires, which the employed and unemployed learners completed, together with the interviews that were conducted with the subject matter experts, as well as the documentations that were collected and reviewed. The learners' portfolios of evidence were examined by looking at the various factors (results, absenteeism rate) of the employed and unemployed learners (Leedy, 2005:186).

The results were drawn from the questionnaires, that the employed and unemployed learners completed, together with the interviews conducted with the subject matter experts and documentation collected. A four-point Likert scale was used (1 - strongly agree, 2 - agree, 3 disagree and 4 - strongly disagree). The following responses were received from the close ended questions.

\section{Demographic reasons for the difference in the performances amongst employed and unemployed learners}

It was found that gender, age and a learner's socio economic status has no influence on their performance as revealed in Tables 1,2 and 3 in the Appendix. This is also portrayed in Figures 1 and 2 in the Appendix. This finding was also corroborated in Tables 11, 12, 13 and 14 in the Appendix. Further probing revealed that older learners find it more difficult to adapt to change. However, some of the unemployed learners who were older than some employed learners had more determination and motivation to successfully complete the learnership (Erasmus et al., 2000:49). The research does, however, reveal that the lower income learners who were the unemployed learners performed better than the employed learners, as they worked towards having financial security.

\section{Personality differences between employed and unemployed learners}

The employed learners failed to understand the value of the learnership and what it can mean for their future career paths, as they are already cleaners and after successful completion of the learnership, they will still only be cleaners. Almost halve of the employed learners (44\%) disagree that studies can improve their future as reflected in Table 5 of the Appendix. Majority of the unemployed learners (80\%) strongly agreed that by having studied, it added value to their life and they were focussed on the benefits of being part of the learnership as shown in Table 6 in the Appendix. The unemployed learners' personality differed vastly from the employed learners, since they experienced the learnership to be one in which they could grow in their career path and, if fortunate enough, may be placed in a permanent job and hence earn a salary. Most of the employed (80\%) and unemployed (98\%) learners agreed that one's attitude can and will have a direct effect on one's success while studying as reflected in Tables 7 and 8 in the Appendix. This indicated that there are slight differences in opinion between the employed and unemployed learners when it comes to their general attitude towards life.

It was noticed that academic and behavioural problems can emanate from a delay in language development, which can negatively influence the learners' reading development, as well as cause social withdrawal and irregular attendance as inferred from Tables 9 and 10 of the Appendix. From the data analysis it was also revealed that the unemployed learners can optimise their performance by balancing their preferred thinking style and decision making abilities towards their studies. This is why their (the unemployed learners) success rate during the learnerships was higher, as the success rate is directly linked to their perceptions. In contrast, the employed learners tend not to be that flexible in their personality and decision making powers and, therefore, less likely to complete a learnership successfully. It was found that employed learners who are already in the system (position) have created their own perceived ideas of the training and have conformed to the thinking style of their colleagues or the other learners within their group.

Both the employed and the unemployed learners were introduced to exactly the same learning programme, yet they experienced it differently. This was caused owing to the belief that lived in the employed learners' minds, and that there would be no benefit from the training and that they would not be promoted after completing the learnership. The employed learners could have formed this perception as a result of their predecessors that completed the learnership, but are still within the same position. Strong negative perceptions are the result of unsatisfied needs. Perceptions that are formed within the employed and unemployed learners' minds influence their attitude, behaviours and decision making powers as far as the learnership programme is concerned.

\section{Individual behaviour of employed and unemployed learners}

When the individuals were part of a group their 'way of 
thinking' (attitude) would have caused others in the group to conform to the rest of the group's thinking style. As the unemployed learners were not really part of a group, they kept their own individual behaviour and this has no effect on their performance during the learnership as revealed from interviews.

\section{Perceptions and individual decision making of employed and unemployed learners}

Findings from the interview indicate that learners make their own choices, whether employed or unemployed, however, they are more open to forming the same norms, perceptions and behaviours when in a homogeneous group.

\section{Educational background differences between employed and unemployed learners}

Employers who entered into a learnership agreement with unemployed learners often have prerequisites for learners who partake in the learnership; one of which is that all learners must have a Grade 10 qualification to enter into the agreement as shown in Tables 17 and Figure 3 in the Appendix. This is to safeguard the employer and learner to ensure that the learner will be able to understand the work. Employers are fearful to employ learners who do not meet the pre-requisite, as they do not want to spend money on training learners who will be unable to participate fully in the training owing to their skills level. Conversely, the employed learners vary in the grade that they obtained owing to not having a pre-requisite set by management to enter into the learning environment as also revealed in Tables 17 and Figure 3 in the Appendix. However, it is incorrect to assume that because some employed learners have obtained higher grades than the unemployed learners, this should automatically imply that they will perform better than the unemployed learners. It can be stated that the urge to obtain knowledge for the unemployed learners is so immense that it prompts them to achieve more than the employed learners.

\section{Motivating financial reasons for differences in performance amongst the employed versus unemployed learners}

The research concludes that money is not the biggest motivator for the unemployed learners to enrol into the learnership agreement as shown in Table 20 and Figure 4 in the Appendix. For most of the unemployed learners' potential job security is the biggest motivator in the sense of being able to earn a more permanent salary to enable them to support their families. Money is, therefore, not related to a learner's success rate during a learnership as shown in Table 21 and Figure 5 in the Appendix. The unemployed learners did, however, feel that they were, to a certain degree, entitled to the learner stipend that they received, as this was used for travelling costs and was also seen as a reward for the work that they conducted at the employer's worksite.

\section{Absenteeism rates of the learners}

The documents reviewed by the researchers indicated that the absenteeism rate of the employed learners were much higher than that of the unemployed learners. The employed learners were often called back into the workplace when there were too few staff members to do the work on a particular day when training was conducted, compared to the unemployed learners who did not have to return to the workplace. The researcher noted that the organisation's supports that are provided to the employed and unemployed learners play a vital role in the success of the learners during their studies. Family supports also play a pivotal role in the performance of employed (86\%) and unemployed (58\%) learners in the learnership programme as revealed in Tables 15 and 16 of the Appendix.

\section{DISCUSSION}

Findings from the interviews, questionnaires and documentation were combined as it addressed the same issues. It emerged from having discussed the demographic reasons for the differences in the performance of the employed and the unemployed learners that gender, age or a learner's socio- economic status (Table 4) has no influence on a learner's performance during learnerships. Findings from the data analysed indicates that employed and unemployed learners formed homogenous groups that interacted with one another. By forming these groups it caused solidarity and cohesion within the two different groups. Although the learners all had their own individual personality, they were more open to forming the same perceptions and behaviours when in a homogeneous group. Within the employed group of learners, there was a strong feeling of camaraderie. The negative energy within the employed group of learners caused them to think negatively about the learnership before engaging with the learning system. The unemployed learner group worked towards the same goal (and this was to find permanent employment), which caused them to work well together and to influence one another in a positive way. Their positive attitude led to the unemployed learners' perception that studies will improve their future and will be the stepping stone for them to become employed. The perception of how the learners view themselves (or in the case of the employed learners -your manager sees the learner), was one of the 
reasons for the difference in performance amongst the employed and unemployed learners.

The research has shown that when employed and unemployed learners form their own informal study groups, the attitudes and behaviours of certain individuals can affect the entire group. The power of the group dynamics in the employed group of learners was so strong that it influenced the way that they thought about the learnership before even entering the learning programme.

Employed and unemployed learners are motivated by different rewards. For the employed learners, they were motivated by finance and having an opportunity to be promoted. The unemployed learners were motivated by security, which meant permanent employment for them. There was no difference detected between the educational backgrounds of these two groups of learners. A majority of the employed and unemployed learners was schooled in formal urban area schools as reflected in Tables 18 and 19 in the Appendix. It is normally the unemployed people who are perceived to have insufficient school training, however, in this situation all of the unemployed learners obtained between a Grade 10 and 12 qualifications. This was a pre-requisite to enter the learnership for the unemployed learners, and provided them with an opportunity to study to ultimately enter the workplace. All unemployed learners completed an extra section in the questionnaire in which they were asked if they entered into the learnership agreement to receive the monthly allowance. The outcome of this data analysis proved that there is no direct relationship between financial incentives and entering into a learnership for the unemployed learners. Therefore, the financial motivation factor had no influence on the unemployed learners' success rate.

\section{RECOMMENDATIONS}

Eight recommendations have been postulated. Five of them are for the benefit of the employed learners, while three of the recommendations are for the benefit of the unemployed learners. The recommendations are outlined as follows.

\section{Learner support for employed learners}

Learner support refers to organisations that ensure that they have the tools available in the workplace, which will assist employed learners to perform to their optimal ability. Learner support can refer to any support mechanism such as counselling, mentoring, learning centres and tutor support. Implementing a 'learner support system' in the organisation will assist employed learners to increase their self-development by creating an opportunity for employed learners to make individual decisions regarding their studies. Another support mechanism would be for organisations to look at customizing course work so that the study material can inculcate examples from the learners' real work environment. Lastly it is important for organisations to train their managers to become assessors, as this will assist them to be efficient mentors for the employed learners during the learnership.

When organisations want to register to become an accredited training provider, the Quality Assurance Body of the specific SETA should request to see the organisation's 'learner support' policy. Therefore, it would be an advantage for any organisation to have the appropriate policies and procedures in place to guide and support the learner throughout the learning intervention.

\section{Establishing learner centres for employed learners}

Employers that embark on learnerships can further support their staff by providing a learning centre where learners can access required and relevant information regarding their subject of study and have areas in which they can study and do their assignments. At this centre, all learning policies should be made available to employed learners so that they can familiarize themselves with the processes of learning, namely assessment policies, learnership agreements, moderation, appeals policy, to name a few. Organisations can also have educational videos available that the students can view, which is specific to their field of study.

\section{Coaching and mentoring of employed learners}

A mentor will fulfil the role of a guide who can help the learners in their career path and development opportunities. A senior manager will normally be the mentor. A coach is more directly involved in the learning process and development of the learners; they will observe the learners while they engage in a practical and provide feedback. A coach can also be an employed learner's direct supervisor. A further recommendation is for managers in the business to undergo assessor and moderator training in order to understand the assessment strategies of the learnership.

\section{‘Buddy system' for employed learners}

Most learners find it difficult to adapt to all the learning methodologies at the beginning of a learnership and, therefore, it is recommended that the employed learners find themselves a colleague that has already completed the learnership who will be able to assist and guide them. The aim of the "buddy system" is for peers to be equipped to understand the assessment outcomes so 
that they can support employed learners.

\section{Motivating the employed learners}

Depending on the level of the NQF, the student can be financially rewarded, by giving the student a once off bonus. A second motivator could be a higher job grade that will be offered to the employed learner who successfully completes the learnership. A third motivational tool, which can be used to increase the employed learner's performance is to explain to them what the value of the course will be for them, should they complete it successfully.

\section{Career readiness programmes for unemployed learners}

It is recommended that the training provider that offers the learnership should conduct a programme for unemployed learners, which will assist them when entering the workplace. These learning programmes will address important intrapersonal skills such as selfawareness, conflict management, communication and relationship building that unemployed learners often struggle with at the beginning of the learnership.

\section{Motivating unemployed learners}

Unemployed learners are reluctant to want to articulate into any further training once they find employment, even if the SETA sponsors the learners to be on the programme. Unemployed learners do not always want to be rewarded with tangible items, and a simple affirmation of compliment can be regarded as a motivator to achieve. For these learners a sense of achievement is more than enough.

\section{Providing employment for unemployed learners}

The biggest motivational factor for unemployed learners is to find permanent employment. Unemployed learners, in most cases intend to find work at the workplace of the lead employer. The workplace at which the learner completed his/her practical experience is generally the one, which will offer the learner a permanent position (upon successful completion of the learnership) if they are satisfied with the performance of the learner during the period in which they have worked there. The lead employer need not make any appointments if he/she does not wish to do so. A positive aspect of unemployed learners is that they are relatively young and, therefore, will not find it difficult to find a job compared to older learners.

\section{Conclusion}

In conclusion, employed learners are motivated by knowing that there will be a salary increase or promotion for them upon completion of the learnership, while the unemployed learners are psychologically motivated by the security of having a permanent position. Employed learners tend to be wary when they do not know why they are doing something, hence there is a need for the organisation to stipulate clearly the reason why the learnership is offered to employed learners and how they can benefit upon completion of the learnership. Before employed learners engage in a learning programme they need to know the value that the particular course will have for them. If it is a mandatory learnership, as in the case of this research study, the employed learners merely want to work through the programme as fast as possible to get it over and done with, as it has no value to them. When a learning programme is clearly defined at the beginning of the programme, learners will know what they are working towards and there will be no unpleasant surprises awaiting them such as practical and summative assessments.

From the research conducted it was found that a learner's personality changes, as they are put in different situations, therefore, it is important for the facilitator to identify when a group of learners conform to a similar personality. As employed and unemployed learners have different needs, they should be treated differently. This is why the initial pre-assessment meeting which is conducted with learners who participate in a learnership is of utmost importance.

Unemployed learners who attended classes regularly and participated in the activities of the session tended to have a higher success rate than employed learners whose attendance was poor. Attendance is important to capture the learner's interest in the programme and to ensure participation, which will lead to better results by the learner. Even though unemployed learners receive a stipend from the SETA to assist them with travelling costs to and from the classes, money is not the biggest motivator for the unemployed learners, although they are grateful to receive it.

The theoretical grounding of this investigation was based on the major objectives and - the interpretation thereof - of the Skills Development Act, No 97 of 1998. The perception that employed learners might naturally perform better than unemployed learners, was of concern to academics, as one of the main focuses of the Skills Development Act was to empower and develop unemployed learners.

A number of remedial measures were postulated in the study to improve the learning outcomes for both the employed and unemployed learners. The outcome of this study will assist all future training companies and learners who enter into a learnership agreement, not only to be aware of the challenges that lie ahead of them, but also 
regarding how they can overcome respective challenges.

\section{REFERENCES}

Alreck PL, Settle R (1985). The survey research handbook. Homewood, IL: Richard D. Irwin, Inc.

Babbie E, Mouton J (2001). The practice of social research. Cape Town: Oxford University Press.

Bayat MS, Fox W (2007). A guide to managing research. Cape Town: Juta.

Birley G, Moreland N (1998). A Practical Guide to Academic Research. London: Kogan Page Ltd

Bendix S (2000). Industrial relations in the new South Africa. 4th ed. Cape Town: Juta.

Bushney M (2003). Training and Development Strategies. Technikon SA.

Erasmus BJ, Nel PS (2007). Managing Training and Development in South Africa. 4th ed. Cape Town: Oxford.

Leedy PD, Ellis J, Ormrod E (2005). Practical research: Planning and design (8th ed.). Upper Saddle River, NJ: Prentice Hall.
Naidu-Ghelani R (Kindly Indicate Initials) (2012). Countries with the highest unemployment rate. CNBC News 15 June 1.

Richards L, Morse JM (2007). Users guide to qualitative methods. 2nd ed. UK: Sage publishers.

Swart J, Mann C, Brown S, Prince A (2005). Human Resource development: Strategy and Tactics 2. First publication. Elsevier: Oxford.

Van Dyk PS, Nel PS, Van Zyl Loedolff P, Haasbroek GD (2001). Training management: a multidisciplinary approach to human resources development in southern Africa. 3rd edition. Cape Town:Oxford University Press.

Vanderstoep SW, Johnston DD (2009). Research Methods for Everyday life: blending Qualitative and Quantitative approaches. San Fransico: Jossy-Bass. 


\section{APPENDIX OF DATA ANALYSIS}

\section{Demographic and socio-economic status}

In this section of the questionnaire employed and unemployed learners were asked to provide details concerning their demographics. The reason why the researcher included this was is to determine whether gender, age and a person's employment status has an effect on the performance levels of employed and unemployed learners. Table 1 contains data that was captured for 50 employed and 50 unemployed learners.

\section{Gender representation of respondents}

The researcher found the importance of identifying respondents' gender as part of the analysis. Table 1 represents the data. Figure 1 presents an illustration of the gender representation.

Of the 50 employed learners, 30 of them are female and 20 are male, while 38 females and 12 males were unemployed. Table 1 reveals that of the 100 respondents, $30 \%$ are employed females and $38 \%$ are unemployed females. Unemployed males represented $12 \%$ of the respondents versus the $20 \%$ of employed males.

\section{Age range of staff members in the learnership}

The rationale behind this information was to find out what the age range is amongst the employed and unemployed learners who were part of the learnership. Table 2 illustrates the data that was obtained.

The frequency table (Table 2) indicates that the employed group of learners were representative within each of the age groups. The age group 18 to 22 represented $14 \%$ of the employed learners; the age group 23 to 27 represented $20 \%$ of the employed learners; and the age group 28 to 32 represented $32 \%$ of the employed learners. In the age group 33 to $37,14 \%$ of employed learners were represented, while in the age group 38 to $42,16 \%$ of employed learners were represented. In the last age group of 43 to $48,4 \%$ of employed learners were represented.

The frequency table (Table 3 ) indicates that the unemployed group of learners were represented in each of the age groups. The age group 18 to 22 represented $50 \%$ of the unemployed learners; the age group 23 to 27 represented $30 \%$ of the unemployed learners and the age group 28 to 32 represented $4 \%$ of the unemployed learners. In the age group 33 to $37,10 \%$ of unemployed learners were represented, while in the age group 38 to $42,0 \%$ of unemployed learners were represented. In the last age group of 43 to $48,6 \%$ of unemployed learners were represented. The same information is displayed in
Figure 2.

\section{Socio-economic status of the learners}

The socio-economic status of a learner examines the social and economic factors in the life of learners that might affect them during learnerships. According to Table 4 , the researcher illustrates the employment status of these learners.

The rationale behind probing the employment status of the learners was important, as it forms the basis of the research objective, namely the difference in the characteristics of employed and unemployed learners that impacts performance. Table 4 shows the number of employed and unemployed learners. The sample size, according to Table $4,50 \%$ of the learners who attended the learnership were unemployed, and the other $50 \%$ were employed.

\section{Personality of learners}

Under this category, all learners received four questions that they had to answer by using a rating scale of (1) Strongly agree; (2) Agree; (3) Disagree and (4) Strongly disagree. The questions that were asked were:

1. Do you believe that studies can improve your future?

2. Does your personality and attitude towards life add to your success in life in spite of your environment?

3. Does the language medium in which you receive training have an influence on your success rate?

By asking the aforementioned questions the researcher intends to determine whether an individual's personality is a result of their heritage or of their environment. Heritage refers to the physical stature or biological makeup of a person, whereas the environment refers to the culture in which the learner was raised. An individual's personality is closely linked with a person's heritage and/or the environment that the person finds $\mathrm{him} /$ herself. The researcher required answers to the aforementioned questions to see whether or not there is any difference in the personality of the employed and unemployed learners, which may have a direct effect on their performance during their studies.

\section{Can studies improve your future?}

The rationale behind this question was to identify whether learners believe that their skills and abilities will have an effect on the success of their career path. Table 5 reflects that $14 \%$ of the employed learners strongly believed that 
Table 1. Gender representation of respondents.

\begin{tabular}{lccc}
\hline & Frequency & Percentage & Percentage cumulative \\
\hline Females employed & 30 & 30 & 30 \\
Females unemployed & 38 & 38 & 68 \\
Males employed & 20 & 20 & 88 \\
Males unemployed & 12 & 12 & 100 \\
Total & 100 & 100 & \\
\hline
\end{tabular}

$\mathrm{n}=100$.

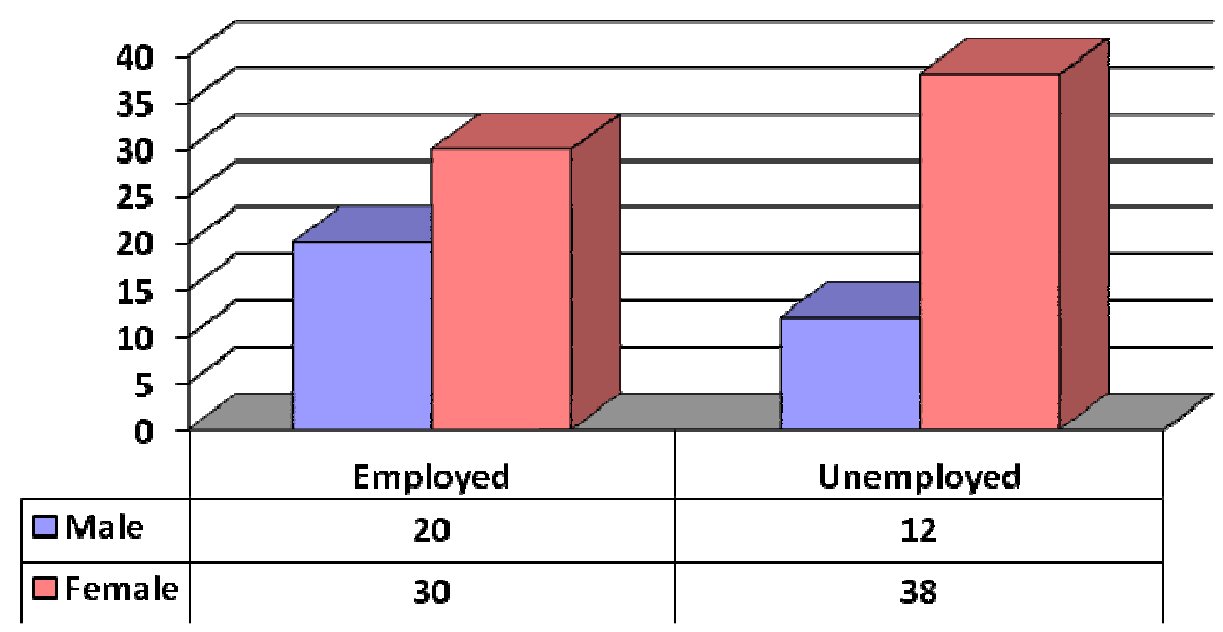

Figure 1. Gender representation of respondents.

Table 2. Age range of employed learners.

\begin{tabular}{cccc}
\hline Age range & Frequency & Percentage & Percentage cumulative \\
\hline $18-22$ & 7 & 14 & 14 \\
$23-27$ & 10 & 20 & 34 \\
$28-32$ & 16 & 32 & 66 \\
$33-37$ & 7 & 14 & 80 \\
$38-42$ & 8 & 16 & 96 \\
$43-48$ & 2 & 4 & 100 \\
Total & 50 & 100 & \\
\hline
\end{tabular}

Table 3. Age range of unemployed learners.

\begin{tabular}{cccc}
\hline Age group & Frequency & Percentage & Percentage cumulative \\
\hline $18-22$ & 25 & 50 & 50 \\
$23-27$ & 15 & 30 & 80 \\
$28-32$ & 2 & 4 & 84 \\
$33-37$ & 5 & 10 & 94 \\
$38-42$ & 0 & 0 & 94 \\
$43-48$ & 3 & 6 & 100 \\
Total & 50 & 100 & \\
\hline
\end{tabular}




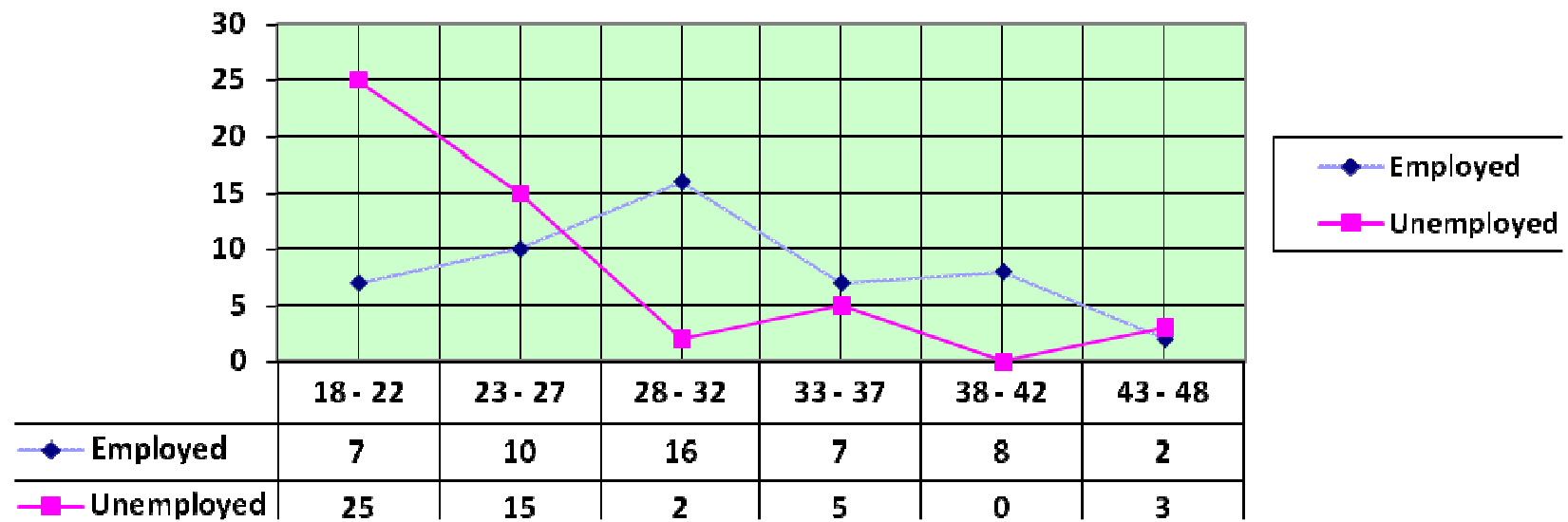

Figure 2. Line chart of learners' age range in frequency format.

Table 4. Socio-economic status of the learners.

\begin{tabular}{lccc}
\hline Status & Frequency & Percentage & Percentage cumulative \\
Employed & 50 & 50 & 50 \\
Unemployed & 50 & 50 & 100 \\
Total & 100 & 100 & \\
\hline
\end{tabular}

Table 5. Can studies improve the future of an employed learner?

\begin{tabular}{lccc}
\hline & Frequency & Percentage & Percentage cumulative \\
\hline Employed: Strongly agree & 7 & 14 & 14 \\
Employed: Agree & 21 & 42 & 56 \\
Employed: Disagree & 17 & 34 & 90 \\
Employed: Strongly disagree & 5 & 10 & 100 \\
Total & 50 & 100 & \\
\hline
\end{tabular}

Table 6. Can studies improve the future of an unemployed learner?

\begin{tabular}{lccc}
\hline & Frequency & Percentage & Percentage cumulative \\
\hline Unemployed: Strongly agree & 18 & 36 & 36 \\
Unemployed: Agree & 22 & 44 & 80 \\
Unemployed: Disagree & 9 & 18 & 98 \\
Unemployed: Strongly disagree & 1 & 2 & 100 \\
Total & 50 & 100 & \\
\hline
\end{tabular}

by investing time in studies can improve one's future. A total of $42 \%$ of employed learners agreed with this statement versus the $34 \%$ of employed learners who disagreed with this statement. A total of $10 \%$ of employed learners strongly disagreed with this statement. The total number of employed learners who agreed comprised $56 \%$ and the total number of employed learners who disagreed totalled $44 \%$.

Table 6 shows that data collected amongst unemployed learners indicates that $36 \%$ strongly agreed; $44 \%$ agreed; $18 \%$ disagreed; and $2 \%$ strongly disagreed with the statement that studies improve the future for unemployed learners. The total number of unemployed learners who agreed was $80 \%$ and the total number of 
Table 7. Attitude: Employed learners.

\begin{tabular}{lccc}
\hline & Frequency & Percentage & Percentage cumulative \\
\hline Employed: Strongly agree & 27 & 54 & 54 \\
Employed: Agree & 13 & 26 & 80 \\
Employed: Disagree & 10 & 20 & 100 \\
Employed: Strongly disagree & 0 & 0 & \\
Total & 50 & 100 & \\
\hline
\end{tabular}

Table 8. Attitude: Unemployed learners.

\begin{tabular}{lccc}
\hline & Frequency & Percentage & Percentage cumulative \\
\hline Unemployed: Strongly agree & 32 & 64 & 64 \\
Unemployed: Agree & 17 & 34 & 98 \\
Unemployed: Disagree & 1 & 2 & 100 \\
Unemployed: Strongly disagree & 0 & 0 & \\
Total & 50 & 100 & \\
\hline
\end{tabular}

Table 9. Language and success rate: employed learners.

\begin{tabular}{lccc}
\hline & Frequency & Percentage & Percentage cumulative \\
\hline Employed: Strongly agree & 13 & 26 & 26 \\
Employed: Agree & 20 & 40 & 66 \\
Employed: Disagree & 14 & 28 & 94 \\
Employed: Strongly disagree & 3 & 6 & 100 \\
Total & 50 & 100 & \\
\hline
\end{tabular}

unemployed learners who disagreed was $20 \%$.

\section{Attitude}

The rationale behind this question was to determine if there is a difference in the attitudes of an employed and an unemployed learner. Learners had to indicate whether they believe that a person's personality and attitude can have an influence on their success rate during the learnership. Table 7 shows students' responses.

Table 7 reflects that $54 \%$ of the employed learners strongly believed that a person's positive attitude towards life can have a positive effect on his/her success in life. A total of $26 \%$ of employed learners agreed with this statement versus the $20 \%$ of employed learners who disagreed with this statement. There were no employed learners who strongly disagreed with this statement. The total number of employed learners who agreed was $80 \%$ and the total number of employed learners who disagreed was $20 \%$.

Table 8 reflects that $64 \%$ of the unemployed learners strongly believed that a person's positive attitude towards life can have a positive effect on his/her success in life. A total of $34 \%$ of unemployed learners agreed with this statement versus the $2 \%$ of unemployed learners who disagreed with this statement. There were no unemployed learners who strongly disagreed with this statement. The total number of unemployed learners who agreed was $98 \%$ and the total number of unemployed learners who disagreed was $2 \%$.

\section{Impact of language on learners' success}

The rationale for this question was to establish if language has an effect on a learner's success rate. The question that was posed to learners was whether they believe that the medium in which they are trained and assessed would have an effect on the success of the training intervention.

Table 9 reflects that $26 \%$ of the employed learners strongly believed that the language in which the training is conducted can have an effect on the success of their studies. A total of $40 \%$ of employed learners agreed with this statement versus the $28 \%$ of employed learners who 
Table 10. Language and success rate: unemployed learners.

\begin{tabular}{lccc}
\hline & Frequency & Percentage & Percentage cumulative \\
\hline Unemployed: Strongly agree & 23 & 46 & 46 \\
Unemployed: Agree & 19 & 38 & 84 \\
Unemployed: Disagree & 8 & 16 & 100 \\
Unemployed: Strongly disagree & 0 & 0 & \\
Total & 50 & 100 & \\
\hline
\end{tabular}

disagreed with this statement. A mere $6 \%$ of employed learners strongly disagreed with this statement. The total number of employed learners who agreed was $66 \%$ and the total number of employed learners who disagreed was $34 \%$.

From the data that was collected for the unemployed learners, $46 \%$ strongly agreed; $38 \%$ agreed and $16 \%$ of unemployed learners disagreed with the statement, namely that language has an effect on the success rate of unemployed learners (Table 10). None of the unemployed learners strongly disagreed with this statement. The total number of unemployed learners who agreed was $84 \%$ and the total number of unemployed learners who disagreed was $16 \%$.

\section{Individual behaviour}

It was essential for the researcher to pose certain questions to the learners in order to evaluate what makes employed and unemployed learners behave differently, if at all. A 4-point Likert scale was used in the questionnaire to obtain the data.

Learners were asked:

- Does age play a role when it comes to your ability to grasp information?

- Does an individual's gender play a role in learning success?

- Is your success in your studies dependant on the values and support that you received from your family during your studies?

\section{Does age play a role when it comes to your ability to understand information?}

Table 11 contains data that was collected from the employed learners by asking them if age has an effect on their ability to grasp information.

When employed learners were asked if their age would have an effect on the success of the training, $26 \%$ of employed learners strongly believed that their age plays a vital role in remembering information that was learnt in the training. A total of $66 \%$ of employed learners agreed with this statement versus the $8 \%$ of employed learners who disagreed with this statement. There were no employed learners who strongly disagreed with this statement. The total number of employed learners who agreed was $92 \%$ and the total number of employed learners who disagreed was $8 \%$.

From the data collected amongst unemployed learners, $24 \%$ strongly agreed; $50 \%$ agreed; and $24 \%$ of unemployed learners disagreed with the statement, while $2 \%$ of unemployed learners strongly disagreed with this statement (Table 12). The statement that was made in the questionnaire was whether age plays a role when it comes to the unemployed learner's ability to understand information. The total number of unemployed learners who agreed was $74 \%$ and the total number of unemployed learners who disagreed was $26 \%$.

\section{Does gender play a role when it comes to your ability to understand information?}

The rationale for this was to ascertain if learners believed that their gender has an effect on their ability to be successful in learnerships.

Table 13 reflects that none of the employed learners strongly agreed with the statement. A total of $6 \%$ of the employed learners agreed with the statement; $84 \%$ of the employed learners disagreed; and $10 \%$ of employed learners strongly disagreed with this statement. The total number of employed learners who agreed was $6 \%$ and the total number of employed learners who disagreed was $94 \%$.

Data that was collected amongst the unemployed learners showed that none of the unemployed learners strongly agreed with the statement; $24 \%$ agreed; and $68 \%$ of unemployed learners disagreed with this statement, while $8 \%$ of unemployed learners strongly disagreed with the statement (Table 14). The total number of unemployed learners who agreed was $24 \%$, and the total number of unemployed learners who disagreed was $76 \%$.

\section{Does the support that you receive from your family assist you in your studies?}

The last question that formed part of this section asked 
Table 11. Does age play a role when it comes to your ability to understand information: employed learners?

\begin{tabular}{lccc}
\hline & Frequency & Percentage & Percentage cumulative \\
\hline Employed: Strongly agree & 13 & 26 & 26 \\
Employed: Agree & 33 & 66 & 92 \\
Employed: Disagree & 4 & 8 & 100 \\
Employed: Strongly disagree & 0 & 0 & \\
Total & 50 & 100 & \\
\hline
\end{tabular}

Table 12. Does age play a role when it comes to your ability to understand information: unemployed learners?

\begin{tabular}{lccc}
\hline & Frequency & Percentage & Percentage cumulative \\
\hline Unemployed: Strongly agree & 12 & 24 & 24 \\
Unemployed: Agree & 25 & 50 & 74 \\
Unemployed: Disagree & 12 & 24 & 98 \\
Unemployed: Strongly disagree & 1 & 2 & 100 \\
Total & 50 & 100 & \\
\hline
\end{tabular}

Table 13. Does gender play a role when it comes to your ability to understand information: Employed learners?

\begin{tabular}{lccc}
\hline & Frequency & Percentage & Percentage cumulative \\
\hline Employed: Strongly agree & 0 & 0 & 0 \\
Employed: Agree & 3 & 6 & 6 \\
Employed: Disagree & 42 & 84 & 90 \\
Employed: Strongly disagree & 5 & 10 & 100 \\
Total & 50 & 100 & \\
\hline
\end{tabular}

Table 14. Does gender play a role when it comes to your ability to understand information: unemployed learners?

\begin{tabular}{lccc}
\hline & Frequency & Percentage & Percentage cumulative \\
\hline Unemployed: Strongly agree & 0 & 0 & 0 \\
Unemployed: Agree & 12 & 24 & 24 \\
Unemployed: Disagree & 34 & 68 & 92 \\
Unemployed: Strongly disagree & 4 & 8 & 100 \\
Total & 50 & 100 & \\
\hline
\end{tabular}

learners if they feel that their studies are dependent on support that they receive from their families (Table 15). Table 16 reflects that $14 \%$ of the employed learners strongly believed that they are more successful in their studies when they have the support of their family members. A total of $44 \%$ of employed learners agreed with this statement versus the $24 \%$ of employed learners who disagreed with this statement and $18 \%$ of the employed learners who strongly disagreed. The total number of employed learners who agreed was $58 \%$ and the total number of employed learners who disagreed was $42 \%$.

Data that was collected amongst the unemployed learners showed that $32 \%$ strongly agreed; $54 \%$ agreed; and $10 \%$ of employed learners disagreed with this statement, while $4 \%$ of employed learners strongly disagreed with the statement. The total number of unemployed learners who agreed was $86 \%$ and the total 
Table 15. Does the support that you (the employed learner) receive from your family have a positive effect on your studies?

\begin{tabular}{lccc}
\hline & Frequency & Percentage & Percentage cumulative \\
\hline Employed: Strongly agree & 7 & 14 & 14 \\
Employed: Agree & 22 & 44 & 58 \\
Employed: Disagree & 12 & 24 & 82 \\
Employed: Strongly disagree & 9 & 18 & 100 \\
Total & $\mathbf{5 0}$ & $\mathbf{1 0 0}$ & \\
\hline
\end{tabular}

Table 16. Does the support that you (the unemployed learner) receive from your family have a positive effect on your studies?

\begin{tabular}{lccc}
\hline & Frequency & Percentage & Percentage cumulative \\
\hline Unemployed: Strongly agree & 16 & 32 & 32 \\
Unemployed: Agree & 27 & 54 & 86 \\
Unemployed: Disagree & 5 & 10 & 96 \\
Unemployed: Strongly disagree & 2 & 4 & 100 \\
Total & $\mathbf{5 0}$ & $\mathbf{1 0 0}$ & \\
\hline
\end{tabular}

Table 17. Highest grade achieved.

\begin{tabular}{lcc}
\hline & Frequency & Percentage \\
\hline Employed: Grade 12 & 15 & 15 \\
Employed: Grade 11 & 16 & 16 \\
Employed: Grade 10 & 10 & 10 \\
Employed: Grade 9 & 5 & 5 \\
Employed: Grade 8 & 4 & 4 \\
Unemployed: Grade 12 & 11 & 11 \\
Unemployed: Grade 11 & 14 & 14 \\
Unemployed: Grade 10 & 25 & 25 \\
Unemployed: Grade 9 & 0 & 0 \\
Unemployed: Grade 8 & 0 & 0 \\
Total & 100 & 100 \\
\hline
\end{tabular}

number of unemployed learners who disagreed was $14 \%$.

\section{Educational background of the learners}

The rationale for this information was to identify, which grade the learners completed and to further identify whether these students were schooled in a rural or urban area. Simply because a learner who joined a learnership was unemployed at the time, does not by any means indicate that the learner does not have a proper educational background; hence the researcher believed that this variable, (namely the learners' educational background) should be ascertained in order to see whether this has any direct effect on learners' performance.

\section{Grade achieved for all learners}

The researcher probed the highest grades that the learners achieved, as illustrated in Table 17.

Table 17 reveals that $15 \%$ of the employed learners obtained a Grade 12 qualification, 16\% obtained Grade $11,10 \%$ obtained Grade 10 and 5\% obtained Grade 12, while $4 \%$ obtained a Grade 8 qualification. A total of $25 \%$ of the 50 unemployed students obtained Grade 10, 14\% of the unemployed learners obtained Grade 11 and $11 \%$ of the unemployed learners obtained Grade 12.

Figure 3 indicates that $15 \%$ of employed learners completed their Grade 12, 16\% completed Grade 11 and $10 \%$ completed Grade 10. From the unemployed group of learners, $11 \%$ completed Grade 12, 14\% completed Grade 11 and 25\% of them completed Grade 10.

\section{Area in which the learner was schooled}

The reason for gathering this information was to identify the area in which the learner was schooled.

Table 18 reveals that $4 \%$ of the employed group of learners were schooled in a rural area, and $96 \%$ of them received schooling in an urban area.

Table 19 reveals that none of the unemployed learners was schooled in a rural area, while $100 \%$ of the unemployed learners received schooling in an urban area. 


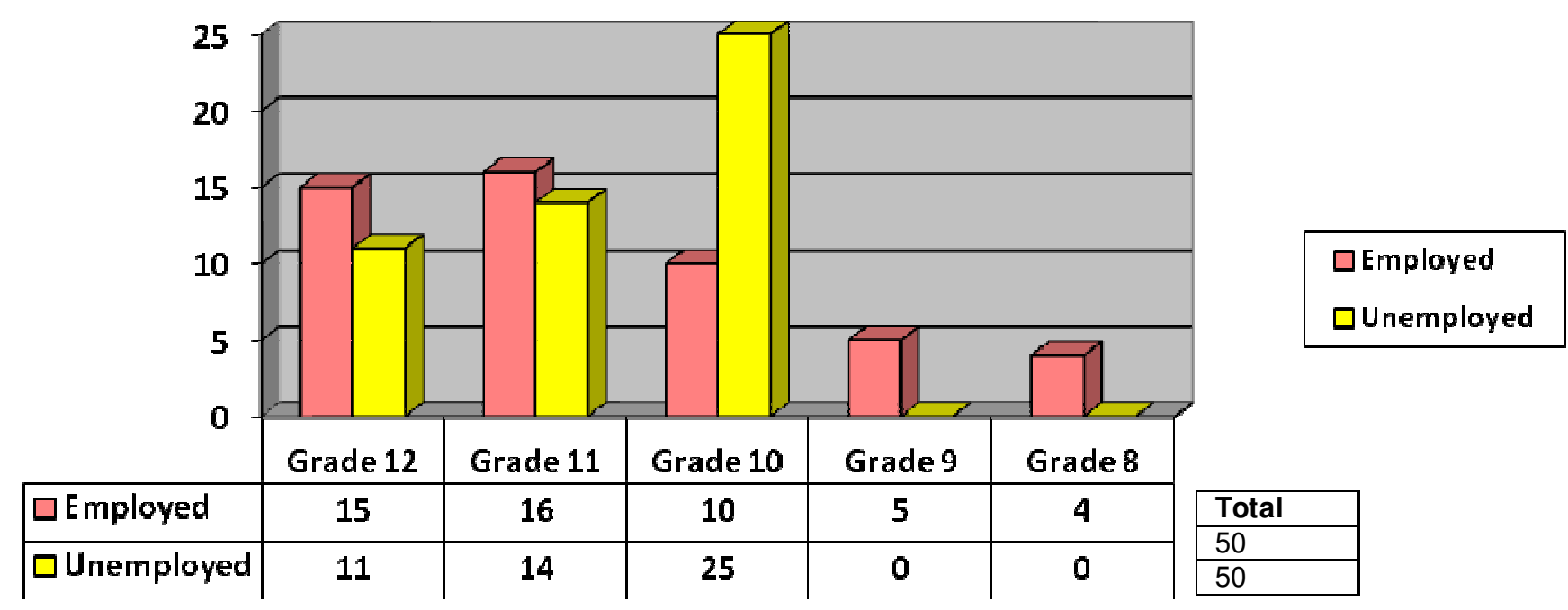

Figure 3. Highest grade achieved.

Table 18. Residential area in which the employed learner was schooled.

\begin{tabular}{lccc}
\hline & Frequency & Percentage & Percentage cumulative \\
\hline Employed: Rural & 2 & 4 & 4 \\
Employed: Urban & 48 & 96 & 100 \\
Total & 50 & 100 & \\
\hline
\end{tabular}

Table 19. Residential area in which the unemployed learner was schooled.

\begin{tabular}{lccc}
\hline & Frequency & Percentage & Percentage cumulative \\
\hline Unemployed: Rural & 0 & 0 & 0 \\
Unemployed: Urban & 50 & 100 & 100 \\
Total & 50 & 100 & \\
\hline
\end{tabular}

Table 20. Learners who received an income at the point of entering the learnership agreement.

\begin{tabular}{lccc}
\hline & Frequency & Percentage & Percentage cumulative \\
\hline Unemployed: Yes & 12 & 24 & 24 \\
Unemployed: No & 38 & 76 & 100 \\
Total & 50 & 100 & \\
\hline
\end{tabular}

\section{Finance}

The unemployed learners were asked about their financial background, in particular if they received any income before entering into the learnership agreement. It was also important for the researcher to investigate the reason why they joined the learnership. Was it for financial security? In Table 20 their answers were noted.

\section{Learners who received an income at the point of entering the learnership agreement}

Table 20 reflects that the number of unemployed learners who received an income at the point of entering into the learnership was $24 \%$. The percentage of unemployed 


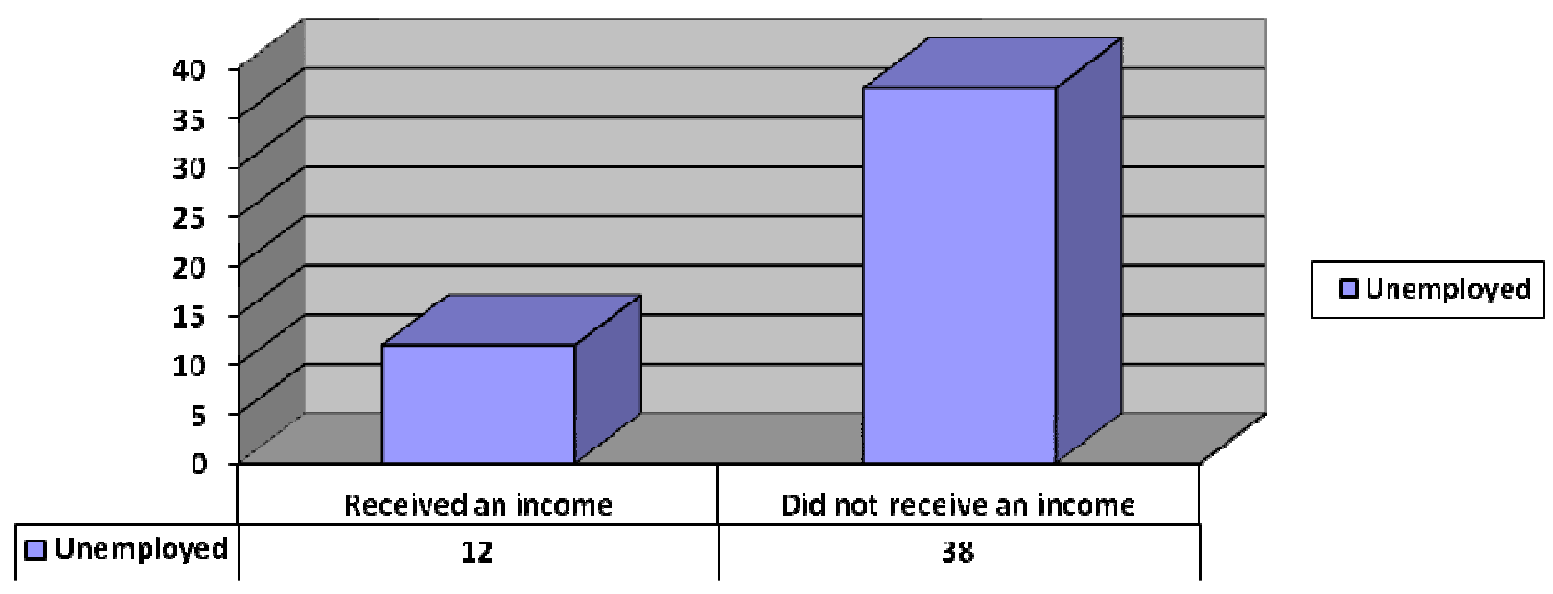

Figure 4. Learners who received an income at the point of entering the learnership agreement.

Table 21. Learners who joined the learnership for financial security.

\begin{tabular}{lccc}
\hline & Frequency & Percentage & Percentage cumulative \\
\hline Unemployed: Yes & 16 & 32 & 32 \\
Unemployed: No & 34 & 68 & 100 \\
Total & 50 & 100 & \\
\hline
\end{tabular}

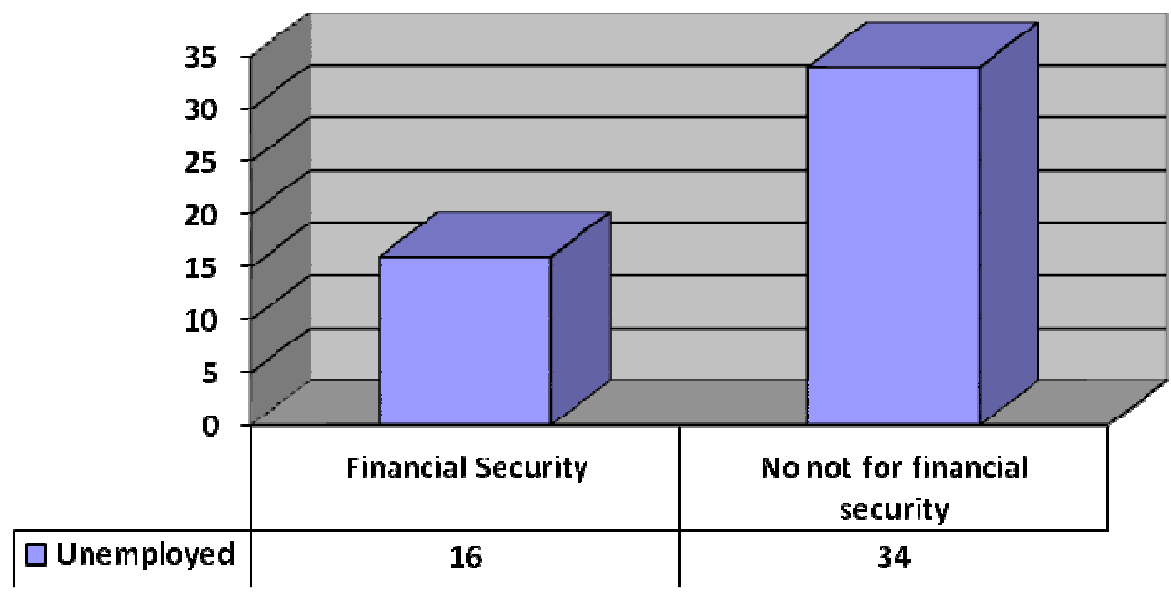

QUnemployed

Figure 5. Learners who joined the learnership for financial security.

learners who did not receive any income prior to entering into the learnership agreement was $76 \%$. In Figure 4, the data from the frequency table was used to show the difference amongst learners who received an income prior to the learnership.

\section{Learners who joined the learnership for financial security}

The next question that was posed to only the unemployed learners was if they joined the learnership for the money that they would receive monthly. For this particular learnership the unemployed learners received an allowance of R240 per week. Table 21 presents the answers that they provided in the questionnaire.

Table 21 reflects that $32 \%$ of the unemployed learners indicated that they entered into the learnership agreement for financial security, while $68 \%$ of unemployed learners indicated the opposite. Figure 5 reflects the same information in the frequency table. 